* Mestranda em Direito pela Universidade de Marília-UNIMAR, bolsista pela CAPES/ PROSUP, advogada. E-mail: jordanavpayao@hotmail. com.

** Possui graduação em Direito pela Universidade Estadual de Londrina (1978), mestrado em Ciências Jurídicas pela Pontifícia Universidade Católica do Rio de Janeiro (1983) e doutorado em Direito pela Pontifícia Universidade Católica de São Paulo (1993). Atualmente é vice-presidente eleita 20092011 do Instituto de Direito Tributário de Londrina, professora da Faculdade de Ciências Gerenciais de Dracena, professora convidada da Universidade Estadual de Londrina e professor titular da Universidade de Marília. Coordenadora do Programa de Mestrado em Direito da UNIMAR. E-mail: mariadefatimaribeiro@uol.com.br.

\section{A EXTRAFISCALIDADE TRIBUTÁRIA COMO INSTRUMENTO DE PROTEÇÃO AMBIENTAL}

\author{
THE EXTRAFISCALITY TAX AS \\ INSTRUMENT OF ENVIRONMENTA \\ PROTECTION
}

\author{
Jordana Viana Payâo* \\ Maria de Fátima Ribeiro**
}

Como citar: PAYÂO, Jordana Viana. RIBEIRO, Maria de Fátima. A extrafiscalidade tributária como instrumento de proteção ambiental. Revista do Direito Público, Londrina, v. 11 , n. 3, p.276-310, dez. 2016. DOI: 10.5433/1980-511X.2016v11n3p276. ISSN: 1980-511X.

Resumo: A proteção ao meio ambiente e a busca pelo desenvolvimento sustentável consistem na prioridade mundial em termos de políticas públicas. O crescimento econômico desenfreado produziu um índice de degradação ambiental irreparável, prejudicando a sobrevivência da presente geração e a possibilidade de existência das próximas gerações. A política tributária surge como instrumento interno eficaz ao combate de práticas lesivas ao meio ambiente e incentivo ao desenvolvimento sustentável, na sua faceta extrafiscal que visa o fomento 
ou restrição de determinados comportamentos dos contribuintes. Por meio de benefícios e incentivos fiscais ocorre a modulação da Ordem Econômica de modo a compatibilizar os ditames ambientais e econômicos. No Brasil, todavia, não há um sistema sólido apto a produzir os efeitos desejados diante da emergencial degradação ambiental. $\mathrm{O}$ objeto central do estudo consiste na análise da atuação do Estado, por meio de políticas públicas tributárias com vistas ao desenvolvimento sustentável, utilizando os mecanismos da extrafiscalidade. Para a abordagem da temática, o texto privilegiou o método dedutivo, partindo da análise do direito fundamental ao meio ambiente na Constituição Federal, incluindo análise bibliográfica e jurisprudencial.

Palavras chave: Desenvolvimento Sustentável. Extrafiscalidade. Meio Ambiente.

Abstract: The protection of the environment and the quest for sustainable developments is a global priority in terms of public policy. Moreover, rampant economic growth produced irreparable environmental degradation, affecting the survival of this present generation and limiting the survival of future generations. Therefore, this tax policy comes as an effective internal tool to combat practices that are detrimental to the environment and encourages sustainable development in its extrafiscality facet, which aims for the restriction of taxpayers' harmful behaviors with tax benefits and incentives. Thus, 
it balances the modulation of the Economic Order with the reconciliation of the environment and the economy. Furthermore, Brazil has a robust system able to produce the desired effects on the fastly emerging environmental degradation. In addition, the main object or central focus of this study is the analysis of the State's performance, with the public tax policies aimed at sustainable developments, which adheres to the mechanisms of extrafiscality. This paper's method of approach is the deductive method: beginning with the analysis of the fundamental right to the environment in the Federal Constitution. However, this research also uses bibliographical and jurisprudential analyses.

Keywords: Sustainable development. Extrafiscality. Environment. 


\section{INTRODUÇÃO}

A proteção ao meio ambiente e o fomento ao desenvolvimento sustentável constituem a prioridade dentre as diversas temáticas em pauta ao redor do mundo. A conscientização quanto a dimensão dos danos ambientais, experimentados pelo universo, faz surgir uma mobilização social que ultrapassa fronteiras em busca de soluções sustentáveis. A busca por instrumentos aptos a concretizar os ditames constitucionais é um desafio cotidiano, em especial dos Poderes Públicos, aos quais competem a tutela da Carta Magna.

O objeto central do estudo consiste na análise da atuação do Estado por meio de políticas públicas tributárias com vistas ao desenvolvimento sustentável, utilizando os mecanismos da extrafiscalidade.

Para a abordagem da temática, o texto privilegiou uma construção dedutiva, partindo da análise do direito fundamental ao meio ambiente na Ordem Constitucional brasileira, analisando na sequência, os mecanismos viabilizadores do equilíbrio entre o sistema financeiro e econômico e o sistema de proteção ambiental, especialmente, a extrafiscalidade tributária. $\mathrm{O}$ texto está fundamentado na doutrina e na jurisprudência.

O desenvolvimento econômico desmedido repercute na degradação ambiental, ao mesmo tempo em que é necessário ao bemestar da sociedade. Nesse ponto incide a tributação como método de compatibilização desses interesses.

Com isso, serão analisadas as desonerações tributárias com vistas ao desenvolvimento sustentável. 


\section{O MEIO AMBIENTE NA ORDEM CONSTITUCIONAL BRASILEIRA}

A tendência da positivação constitucional do direito ao meio ambiente protegido, decorreu das manifestações protagonizadas por organizações internacionais que, diante do cenário de degradação ambiental fruto da evolução industrial e tecnológica e da conscientização ecológica, detectaram a necessidade de uma mobilização a nível mundial.

A Organização das Nações Unidas (ONU), realizou a primeira Conferência Mundial sobre o Homem e o Meio-ambiente em 1972, da qual originou a Declaração de Estocolmo, que reconheceu o meio ambiente sadio e equilibrado como direito de todos e indispensável a existência humana.

AComissão Mundial sobre o Meio Ambiente e o Desenvolvimento da ONU elaborou o Relatório de Brundtland em 1987, prevendo o ideal de desenvolvimento sustentável.

Apenas duas décadas após a referida Conferência, em Estocolmo houve nova movimentação internacional na seara ambiental. Ocorreu no Rio de Janeiro a Conferência das Nações Unidas sobre Meio Ambiente e Desenvolvimento, também conhecida como "Cúpula da Terra", "Eco 92" ou ainda "Rio 92", a qual teve como fruto o tratado internacional conhecido como Convenção-Quadro das Nações Unidas sobre a Mudança do Clima-CQNUMC. Referida Conferência foi ratificada pelo Brasil em 1988, cujo objetivo primordial foi desenvolver o modelo de desenvolvimento sustentável, ou seja, aquele que leva em consideração que há níveis de recuperação do meio ambiente que devem ser respeitados, sob pena dos danos causados serem irreversíveis.

Diante da falta de efetividade plena dos referidos documentos 
internacionais, até mesmo por conta da omissão de sanções pelo desatendimento de suas orientações, ocorreram diversas atualizações ao longo dos anos, visando o compartilhamento de dados, fiscalização e até punição dos Estados signatários, tal qual ocorreu com o Protocolo de Quioto em 1997.

Diante de todo histórico de mobilização internacional e da alarmante manifestação dos efeitos decorrentes da degradação ambiental no cotidiano das pessoas, um planejamento com vistas a mitigar os danos ambientais tornou-se uma prioridade local. Independentemente do nível de desenvolvimento econômico, social ou tecnológico do país a questão ambiental ganhou assento preferencial no Brasil.

A Constituição Federal de 1988 ao estabelecer a questão ambiental e de desenvolvimento, de maneira abrangente, foi rica em disposições, normas e princípios voltados à dignidade da pessoa humana, à qualidade de vida, ao bem-estar social, do acesso ao trabalho, nas políticas do meio ambiente, nas políticas de desenvolvimento, na política agrária, na política tributária entre outras. Tais disposições, são prescrições constitucionais que dependem das efetivações, por meio de políticas públicas.

A Carta Política brasileira dispõe sobre a competência legislativa dos entes políticos sobre meio ambiente (artigos 24 e 30). Esses entes poderão, dentro das disposições que lhes são pertinentes, estabelecer políticas de incentivos fiscais, de isenções de tributos, entre outras, que possam contemporizar questões que, consequentemente, venham contribuir para o meio ambiente saudável, sem deixar de arrecadar valores para os cofres públicos.

A exploração indiscriminada dos recursos naturais renováveis provoca frequentemente prejuízos ambientais, com acentuados lucros 
na exploração econômica, onerando a sociedade. A garantia ambiental constitucional brasileira é uma das mais modernas internacionalmente, quanto à qualidade de vida e a proteção ao meio ambiente ecologicamente equilibrado para as presentes e futuras gerações (artigo 225).

A Constituição Federal inaugurou, de maneira específica e global, a proteção ao meio ambiente. Dentre as diversas disposições constitucionais que abordam o tema e que serão devidamente citadas oportunamente, merece destaque o artigo 225 da Constituição:

Todos têm direito ao meio ambiente ecologicamente equilibrado, bem de uso comum do povo e essencial à sadia qualidade de vida, impondo-se ao Poder Público e à coletividade o dever de defendê-lo e preservá-lo para as presentes e futuras gerações (BRASIL..., 2012, p. 127).

O legislador constituinte reconheceu expressamente o direito fundamental ao meio ambiente ecologicamente equilibrado, que consiste em um direito fundamental de terceira dimensão, coletivo, difuso e de natureza transindividual, ou seja, um bem de uso comum do povo.

Mostra-se clara a necessidade de medidas de proteção nas três esferas de governo, vez que, trata-se de um interesse coletivo. Dezen Junior (2003), ao comentar o caput do art. 225 da Constituição Federal, ressaltou que o Supremo Tribunal Federal decidiu que, a questão do direito ao meio ambiente ecologicamente equilibrado, afirma-se como típico direito de terceira geração e se constitui prerrogativa jurídica de titularidade coletiva.

A Constituição brasileira prevê que a gestão ambiental é uma atribuição conjunta da União, dos Estados, do Distrito Federal e dos Municípios (art. 225). Além das disposições do capítulo destinado 
ao meio ambiente, deve este ser interpretado em conjunto com o art. 170, do mesmo diploma legal, que dispõe sobre a ordem econômica, ressaltando a intervenção do Estado nas atividades econômicas que podem gerar impactos ambientais. Os princípios que informam a ordem econômica ambiental e o Direito Ambiental, devem compatibilizar o desenvolvimento econômico com a proteção ambiental e a adequação dos propósitos, meios e fins dos conteúdos jurídicos.

O gozo de um meio ambiente saudável repercute diretamente no ideal da dignidade da pessoa humana, uma vez que compromete toda uma cadeia de direitos do ser humano, desde a saúde, a moradia, o lazer, a educação e o exercício do pleno emprego.

Merece destaque a afirmativa de Amado:

Portanto, as pessoas têm direito a um mínimo existencial ecológico, para gozar de uma vida digna, pois sem uma água limpa para beber, um ar puro para respirar e um alimento sem agrotóxicos ou outros males todos os demais direitos fundamentais ficarão prejudicados, em especial o direito à saúde (AMADO, 2014, p. 51).

É importante ressaltar que o enfrentamento dos danos ambientais e a busca de um desenvolvimento sustentável são de caráter universal. Os efeitos nocivos da degradação ao meio ambiente repercutem em todo o mundo, independentemente da origem. Sendo assim, o princípio da cooperação entre os povos tem aplicabilidade direta no que se refere ao meio ambiente. Por óbvio, porém, cada território possui peculiaridades e níveis diferenciados de degradação, logo, o desenvolvimento de forma direcionada é essencial para o sucesso da empreitada. 
O diploma constitucional dispõe sobre a ordem econômica a partir do artigo 170 e estabelece dentre seus princípios norteadores a defesa do meio ambiente, conforme dispõe:

Art. 170. A ordem econômica, fundada na valorização do trabalho humano e na livre iniciativa, tem por fim assegurar a todos existência digna, conforme os ditames da justiça social, observados os seguintes princípios: [...] VI - Defesa do meio ambiente, inclusive mediante tratamento diferenciado conforme o impacto ambiental dos produtos e serviços e de seus processos de elaboração e prestação; (BRASIL, 2012, p. 107).

O desenvolvimento econômico a todo custo, de maneira desenfreada e voltado apenas ao acumulo de riqueza, não mais condiz com a ordem econômica constitucional atual. Dentre os objetivos fundamentais da República Federativa do Brasil, elencados no artigo $3^{\circ}$, está a garantia ao desenvolvimento nacional, conjuntamente com a construção de uma sociedade livre, justa e solidária, a erradicação da pobreza e da marginalização.

Sob uma visão sistemática do texto constitucional resta clara a necessária adequação dos pilares econômicos, ou seja, do desenvolvimento nacional, com os ditames sociais, que remetem à dignidade da pessoa humana. O direito fundamental ao meio ambiente saudável, constitui relevante pilar da dignidade humana por ser garantidor do mais elementar dos direitos, qual seja, o direito à vida. Portanto, afunilando a análise, o desenvolvimento econômico deve evoluir junto ao desenvolvimento sustentável. 
O desenvolvimento sustentado vem destacado nos escritos de Milaré:

É por isso que hoje se fala com tanta insistência em desenvolvimento sustentado ou ecodesenvolvimento, cuja característica consiste na possível conciliação entre o desenvolvimento, a preservação ecológica e a melhoria da qualidade de vida do homem. É falso o dilema 'ou desenvolvimento ou meio ambiente', na medida em que, sendo uma fonte de recursos para o outro, devem harmonizar-se e complementar-se. Compatibilizar meio ambiente e desenvolvimento significa considerar os problemas ambientais dentro de um processo continuo de planejamento, atendendo-se adequadamente ás exigências de ambos e observando-se as suas inter-relações particulares a cada contexto sociocultural, político, econômico e ecológico dentro de uma dimensão tempo/espaço. Em outras palavras, isto significa dizer que a política ambiental não deve constituir em obstáculo ao desenvolvimento. (MILARÉ, 2007, p. 211).

Os princípios ambientais orientam o desafio que consistem na compatibilização entre o crescimento econômico e a garantia ao meio ambiente saudável. A pedra de toque da discussão consiste no princípio do desenvolvimento sustentável, previsto expressamente na Declaração do Rio (1992, p. 1), Princípio 4: "Para se alcançar um desenvolvimento sustentável, a proteção ambiental deve constituir parte integrante do processo de desenvolvimento e não pode ser considerada separadamente". O Relatório de Brundtland foi ainda mais específico ao conceituar o 
desenvolvimento sustentável como aquele que satisfaz as necessidades presentes, sem comprometer a capacidade das gerações futuras de suprir as próprias necessidades.

Destas considerações, pode-se verificar que continua sendo um grande desafio, na ordem econômica, a implementação do princípio constitucional do desenvolvimento sustentável. Por isso mesmo, é possível afirmar que as questões ambientais estão interligadas com as questões econômicas e sociais, e, que a efetividade da proteção ambiental depende do tratamento globalizado e o conjunto de todas elas, ou seja, pelo Estado e pela sociedade.

As necessidades do ser humano são ilimitadas, em contrapartida aos recursos ambientais naturais que são limitados. Sendo assim, deve haver uma razoabilidade na fruição dos mesmos com vistas ao acautelamento das futuras gerações.

O desenvolvimento econômico desmedido e desproporcional à capacidade de suporte ambiental, deu causa a uma devastadora degradação ambiental. Daí a iminente necessidade de um desenvolvimento que respeite os limites ecológicos e as futuras gerações. $\mathrm{O}$ desenvolvimento sustentável, por sua vez, pressupõe o crescimento econômico aliado à qualidade de vida e à justiça social. (RIBEIRO; FERREIRA 2005, p. 36 apud, TORRES, 2005, p. 661).

O direito fundamental ao meio ambiente sadio não é absoluto, portanto, não pode inviabilizar o desenvolvimento econômico que, por sua vez, também contribui com a justiça social. Deve haver uma adequação, exatamente como propõe o princípio do desenvolvimento sustentável.

Os princípios da prevenção e da precaução são inerentes a 
natureza do direito fundamental ao meio ambiente equilibrado. Após a consumação dos danos ao meio ambiente é improvável a reversão dos efeitos nocivos, e, por vezes até impossível. A prevenção e a precaução são mecanismos essenciais diante de uma comprovada possibilidade de dano ou sendo o mesmo já comprovado.

Inerente ao pilar do desenvolvimento sustentável, o princípio do poluidor-pagador representa um mecanismo útil na tentativa de frear o consumo desenfreado dos recursos naturais, prevendo que cabe ao poluidor compensar ou reparar o dano causado pela atividade desenvolvida. Assim, o poluidor deve responder pelos custos sociais da degradação causada, agregando esse valor ao custo produtivo da atividade, evitando a privatização dos lucros e a socialização dos prejuízos.

O Princípio do Usuário-pagador estabelece uma espécie de contraprestação diante do uso dos recursos naturais, independentemente de haver degradação ambiental, como acontece atualmente com o uso da água. Há uma tendência mundial em cobrar pelo uso dos recursos naturais, em especial os mais escassos e não renováveis, de modo que os recursos financeiros arrecadados sejam também revertidos para fins ecológicos.

O princípio da cooperação entre os povos é especialmente relevante, considerada a abrangência dos efeitos oriundos da degradação. É essencial a mobilização das diversas nações no sentido de buscar medidas saneadoras. Conforme prevê o artigo $4^{\circ}$ da Carta Magna, o princípio da cooperação deve nortear as relações internacionais do Brasil, e, nessa seara, os aspectos ambientais são prioridade, como pode ser observado nas lições seguintes defendidas por Derani:

Pode-se dizer que o princípio da cooperação 
é resultado de uma divisão de funções dentro da ordem econômica fundada nas relações de mercado. Sua concretização, como princípio do direito ambiental e do direito econômico simultaneamente, se dá, por exemplo, quando determina a divisão dos custos de uma política preventiva de proteção ambiental, implicando uma negociação constante entre as atividades do Estado e do cidadão (DERANI, 2005, p. 641).

Pretendendo a concretização de todos os princípios ambientais, merece destaque o princípio da natureza pública (ou obrigatoriedade) da proteção ambiental, que consiste no dever irrenunciável do Poder Público de promover a proteção ambiental, uma vez que se trata de um direito difuso e de uso comum do povo.

O Estado, na condição de agente regulador da Ordem Econômica Ambiental, deve editar normas voltadas ao desenvolvimento sustentável aptas a harmonizar a proteção ao meio ambiente e o crescimento econômico bem como conscientizar a população a respeito de seus deveres ecológicos.

A defesa do meio ambiente consiste em um dos princípios norteadores da Ordem econômica constitucional, portanto, a intervenção do Estado na economia deve considerar aspectos ambientais. De maneira geral, cabe ao Estado garantir mecanismos de proteção ao meio ambiente e fomentar o desenvolvimento de maneira sustentável.

Segundo Grau (2005, p. 148) há três modalidades de intervenção estatal no domínio econômico, quais sejam, a intervenção por absorção ou participação, por direção e por indução. No primeiro caso, o Estado intervém na atividade econômica em sentido estrito, ou seja, atua 
como sujeito econômico. Quando o faz por absorção, o Estado assume integralmente o controle dos meios de produção em determinado setor da atividade econômica em sentido estrito, ou seja, em regime de monopólio estatal. Enquanto que na modalidade por produção, também em determinada atividade econômica, o Estado atua em regime de competição com as empresas privadas. A intervenção por direção consiste no estabelecimento de normas de comportamento compulsório, dirigidas aos sujeitos da atividade econômica em sentido estrito. O mecanismo de intervenção denominado indução, por sua vez, ocorre quando o Estado manipula os mecanismos de intervenção de acordo com as leis que regem o funcionamento dos mercados. Na intervenção por indução o Estado não atua de maneira compulsória, não há a imposição de comportamentos. Ao contrário, os instrumentos indutores, induzem, fomentam ou direcionam determinadas ações mediante contrapartida estatal, dessa forma o poder público molda a economia.

Nesse cenário surge as políticas tributárias fiscal ou extrafiscal como instrumento de intervenção estatal na economia mediante indução. Referidas políticas consistem em poderosos mecanismos de modelagem da ordem econômica no Brasil, e, é essencial seus direcionamentos para a concretização dos ditames constitucionais, dentre os quais, o direito fundamental ao meio-ambiente saudável.

O Sistema Tributário consiste no conjunto de regras, princípios e mecanismos formadores da política tributária nacional. Os princípios tributários ora legitimam ora limitam o poder de tributar, como por exemplo, os Princípios da Isonomia tributária, da capacidade tributária, da legalidade e da vedação do tributo com natureza de confisco. Noutro giro, está o rol de regras regulamentadoras da atividade tributária estatal, dentre as quais o Código Tributário Nacional. 
A tributação consiste no mecanismo por meio do qual o Estado, impõe ao cidadão o dever de quitar determinado ônus diante da ocorrência de determinado fato. Em uma análise inicial a finalidade da tributação parece restringir-se a arrecadação de moeda aos cofres públicos, todavia, conforme já apontado, pode e deve produzir efeitos em outros setores que não o meramente financeiro, como no caso o setor ambiental, conforme explica Bernardi (2008, p. 12):

A política fiscal é uma opção política de quem detém e exerce o poder soberano do Estado. De acordo com esta, arrecadam-se receitas para a manutenção da máquina estatal. Todavia, ela pode, também, ter como objetivo uma reforma social, incentivando o desenvolvimento nacional e conduzindo a uma melhor distribuição da renda nacional.

É possível identificar dois aspectos existentes na tributação: a fiscalidade e a extrafiscalidade, que se diferenciam quanto aos efeitos. Os tributos ditos fiscais pretendem a arrecadação de recursos aos cofres públicos, ou seja, detém uma natureza iminentemente arrecadatória. Enquanto que o tributo extrafiscal não se limita ao repasse de recursos do contribuinte ao Estado, mas sim, pretende interferir na ordem econômica e social, mediante o fomento ou a limitação de comportamentos dos entes privados. Há defensores da tese que desnatura referida diferenciação, uma vez que todo tributo extrafiscal seria também fiscal em sua essência. $\mathrm{Na}$ verdade, o que se identifica é uma preponderância do caráter arrecadatório ou extrafiscal. Referida temática será abordada mais especificamente na seara da tributação ambiental.

Nesse sentido, convém destacar a constatação da necessidade de 
uma política fiscal voltada a cumprir os ditames constitucionais em todos os aspectos, não puramente econômico, como a aplicação de política tributária em favor do desenvolvimento sustentável e da proteção do meio-ambiente.

Afirma Diego Bomfim, que não existem tributos ambientais, do mesmo modo que não existem tributos redutores de desigualdades regionais ou tributos concorrenciais. $\mathrm{O}$ que o ordenamento jurídico permite é que a defesa do meio ambiente seja tomada como um fundamento relevante para a instituição de normas tributárias extrafiscais, estimulando ou desestimulando condutas. Ainda que se reconheça tal finalidade, é preciso pontuar uma série de limitações que o regime ributário impõe, o que reduz a amplitude da criação de tributos orientados à proteção ambiental (BOMFIM, 2015, p. 103).

\section{AEXTRAFISCALIDADE COMO MECANISMO DE PROTEÇÃO AMBIENTAL E FOMENTO AO DESENVOLVIMENTO SUSTENTÁVEL}

Carrazza, observa que:

Há extrafiscalidade quando o legislador, em nome do interesse coletivo, aumenta ou diminui as alíquotas e/ou a base de cálculo dos tributos, com o objetivo principal de induzir os contribuintes a fazer ou a deixar de fazer alguma coisa. Por aí se vê que a extrafiscalidade nem sempre causa perda de numerário; antes, pode aumenta-lo, como, por exemplo, quando se exacerba a tributação sobre o consumo de cigarros (CARRAZZA, 2008, p. 109). 
A partir daí, além da imposição clássica, limitada à arrecadação de recursos financeiros para o atendimento das necessidades públicas, se estabelece a tributação extrafiscal, voltada à ordenação da economia e das relações sociais. (SABBAG, 2013, p. 158).

Compete aos Poderes públicos o desenvolvimento de políticas públicas que viabilizem o gozo dos direitos fundamentais. Nesse sentido, a garantia ao meio ambiente saudável pressupõe uma efetivação estatal. A extrafiscalidade tem se revelado um poderoso expediente a serviço do Estado, seja inibindo condutas indesejáveis, seja estimulando comportamentos salutares no campo ecológico. Nessa visão, é notória a importância da intervenção estatal por meio da tributação com objetivos regulatórios.

Em virtude da necessidade de medidas urgentes para a proteção do meio ambiente e, em consequência, para a segurança da própria humanidade, os instrumentos econômicos expressos em políticas fiscais são de grande valia, podendo o estado ir muito além da arrecadação de tributos, direcionando suas políticas públicas para o adequado desenvolvimento socioeconômico das necessidades ambientais como acentua Cavalcante (2012, apud GRUPENMACHER, 2012, p. 121).

É importante ressaltar que a utilização da extrafiscalidade tributária voltada à proteção ambiental ou ao estabelecimento de um desenvolvimento sustentável, não implica necessariamente na instituição de novas espécies tributárias. Há necessidade de adequar os tributos já existentes ás finalidades ecológicas e a regulação do mercado de modo a torná-lo sustentável.

Quais as possibilidades de as normas fiscais interferirem nas políticas públicas ambientais? Os estados contemporâneos têm o desafio de transformar as diretrizes teóricas sobre o desenvolvimento sustentável 
em políticas públicas coerentes e eficientes. Não há como definir uma só política pública internacional, considerando as especificidades de cada país, mas é possível criar políticas públicas locais e regionais com base em um conceito comum de sustentabilidade internacional, traçando princípios que sejam o senso comum da humanidade. Esta tendência foi observada nas últimas convenções internacionais. O papel dos estados nesta transformação é essencial, como bem esclarece Ferreira (2004, p. $93-94)$.

E nessa trilha, Heleno Taveira Torres pontua que:

A tentativa de construção de um Sistema Tributário Ambiental tem sido permanentemente referida como um dos principais instrumentos do desenvolvimento econômico sustentável, com o propósito de alcançar uma efetiva "economia verde" (green economy). De fato, os tributos, em suas distintas técnicas de aplicação, podem ser usados para reduzir ou eliminar externalidades ambientais, estimular a inovação e assegurar proteção ao meio ambiente, numa interação permanente com o aprimoramento da educação, da redução da pobreza e da melhoria da qualidade de vida da população (TORRES, 2012a, p. 1).

A estruturação da tributação extrafiscal no campo ambiental pode abranger instrumentos fiscais de diversas naturezas, e, que não constituam necessariamente em renúncia de receita. A modulação de alíquotas de acordo com a atividade desenvolvida e o índice de poluição a ela inerente ou da concessão de benefícios fiscais (tais como incentivos e subsídios) para o desenvolvimento de tecnologias limpas e iniciativas 
positivas ao meio ambiente, são exemplos dessa afirmativa.

As funções da tributação ambiental são classificadas de acordo com a atividade a ser alcançada por meio de sua adoção, podendo ter: i) função indutora: induz a comportamentos ambientalmente adequados e/ ou premia as condutas mais favoráveis (internalização das externalidades positivas); ii) função restauradora: restaura os danos ambientais já ocorridos; e iii) função redistributiva: redistribui os custos ambientais das atividades causadores de danos (internalização das externalidades negativas) (CAVALCANTE, 2012, p. 177).

A tributação ecológica consiste basicamente no emprego de instrumentos tributários aptos a gerar os recursos necessários à prestação de serviços públicos de fins ambientais (aspecto fiscal) bem como, para orientar o comportamento dos contribuintes a respeito da proteção ambiental (aspecto extrafiscal). (COSTA, 2005, p. 330).

$\mathrm{O}$ exercício da extrafiscalidade a favor do meio ambiente é fundamental, especialmente em países como o Brasil, com vastas áreas verdes e desigualdades regionais acentuadas pela extensão territorial avantajada.

O papel do tributo como instrumento de intervenção na atividade econômica, seja qual for a sua espécie, deverá ser o de indutor de atividades ambientalmente corretas, propiciando uma adequação do desenvolvimento socioeconômico às necessidades ambientais.

Grey destaca que se faz necessária a intervenção do poder público:

[...] nas esferas do desenvolvimento econômico e social, a fim de que seja realizado o controle efetivo do uso dos recursos naturais. Nesse sentido é que a tributação ambiental surge 
como um dos instrumentos de controle para o desenvolvimento econômico. Os padrões atuais de consumo revelam-se como sendo insuportáveis a longo prazo, sendo que os tributos se apresentam como uma utilíssima ferramenta na tentativa de manutenção de um meio ambiente saudável (GREY, 2009, p. 82).

Como toda e qualquer atuação do Estado, a tributação precisa ser pautada nos princípios constitucionais, em especial quando for de natureza extrafiscal, já que expressa uma intervenção do Estado na Ordem econômica, seja incentivando ou restringindo a inciativa privada.

O princípio da supremacia do interesse público sobre o privado significa que a atuação soberana do Poder Público deverá ser pautada na busca do interesse coletivo.

A preservação ambiental vem, também, para garantir a segurança e o próprio direito à vida (artigo $5^{\circ}$ da Constituição Federal), visto que a degradação provoca reações representativas, expondo as pessoas a perigos e riscos relevantes que atentam contra suas próprias vidas.

Desse modo, o direito à vida, constitui-se no alicerce do direito ao meio ambiente ecologicamente equilibrado. A partir desse entendimento, o meio ambiente passa a ser percebido, também, como direito coletivo, e sua preservação, como fator para o desenvolvimento. Deve-se, então, ser compatibilizado o crescimento econômico com melhores condições de vida para as pessoas (MEDEIROS, 2011, p. 120).

No mesmo sentido, Eros Roberto Grau ensina que:

O princípio da defesa do meio ambiente conforma a ordem econômica (mundo do ser), informando substancialmente os princípios da garantia do 
desenvolvimento e do pleno emprego. Além de objetivo, em si, é instrumento necessário - e indispensável - à realização do fim dessa ordem, o de assegurar a todos a existência digna. Nutre também, ademais, os ditamos da justiça social. Todos têm direito ao meio ambiente ecologicamente equilibrado, bem de uso comum do povo (GRAU, 2005, p. 251).

O princípio da proporcionalidade, por sua vez, deve nortear a incidência dos tributos, visando evitar excessos e até mesmo intervenções desnecessárias em determinado setor da economia, bem como, afastar a nociva prática da guerra fiscal entre os territórios.

A relação entre a proteção ambiental e livre concorrência deve ser observada pelo Estado, que deverá adotar medidas de controle e de sanções administrativas e penais ou utilizar a instrumentalidade de tributos. Se, de um lado, esses podem assegurar a livre concorrência no plano nacional, por outro lado, podem diminuir drasticamente a competitividade no plano internacional (ROTHMANN, 2009, p. 360).

$\mathrm{O}$ fato da finalidade extrafiscal atingir interesses públicos relevantes, como o próprio meio ambiente, não autoriza ilegalidades ou violações aos ditames constitucionais básicos. Além do mais, conforme já apontado, não se trata de um ordenamento tributário novo, exclusivamente com finalidade tributária, estando sujeito ao ordenamento jurídico geral, como pode ser observado nas lições de Cavalcante:

Desta forma, não há que se criar uma conceituação específica de tributo ambiental, considerando que já há uma definição do gênero no art. 3. ${ }^{\circ}$, do Código Tributário Nacional Brasileiro. Não se 
trata de uma espécie nova, mas sim de uma nova motivação. Os tributos com fins ambientais, em regra, também não serão exceção à aplicabilidade dos princípios constitucionais tributários (CAVALCANTE, 2012, p. 91).

Além dos princípios constitucionais apresentados para a questão em pauta, devem ser observados também os princípios da legalidade e da isonomia que são inerentes à extrafiscalidade entre outros.

\section{DESONERAÇÕES TRIBUTÁRIAS AMBIENTAIS}

Tributação ambiental pode ser entendida como o emprego de instrumentos tributários, com finalidade de geração de recursos para o custeio de serviços públicos de natureza ambiental bem como a orientação do comportamento dos contribuintes para a preservação do meio ambiente.

O Sistema Tributário brasileiro possui alguns tributos com incidências aleatórias sobre situações que podem ensejar o desenvolvimento de atividades econômicas com consequências ambientais. Desta forma, a seletividade de alíquotas nos tributos sobre circulação, produção e consumo, deveria ser não somente em função de sua essencialidade, mas também em consonância com os artigos ambientalistas ( $5^{\circ}$ XXVII, 170 e 225 da Constituição Federal), em razão da degradação do meio ambiente, da retirada de recursos não renováveis ou mesmo do tempo de duração do produto.

A adoção de medidas de intervenção serve para implementação de políticas ambientais, não apenas como forma de arrecadar tributos e gerar receitas, mas principalmente como instrumento para a promoção 
de condutas ambientalmente adequadas. Essas políticas devem encontrar um equilíbrio entre os custos da poluição e os custos de seu controle. Seja pela imposição de tributos, seja pela concessão de subsídios, o Estado pode incrementar políticas públicas de preservação ambiental.

O artigo 170, inciso VI da Constituição Federal, buscando conciliar a atividade econômica com a defesa do meio ambiente, determina "tratamento diferenciado conforme o impacto ambienta dos produtos e serviços e seus processos de elaboração e prestação". Portanto, a tributação pode ser utilizada para preordenar condutas, de modo a fazêlas para prestigiar o desenvolvimento sustentável do meio ambiente.

As possibilidades de utilização dos instrumentos tributários para a defesa do meio ambiente são variadas, tais como, a modulação das bases de cálculo dos tributos, a concessão de isenções ou os incentivos fiscais. A concessão de incentivos e benefícios fiscais não pode implicar em privilégios desmedidos que fatalmente prejudicariam a ordem econômica, violando preceitos constitucionais básicos como a isonomia tributária, a legalidade, a capacidade contributiva e a livre iniciativa. Para que a redução da carga tributária, em todas as suas espécies, seja considerada idônea, deve ser desenvolvida de acordo com a Constituição Federal e a Lei de Responsabilidade Fiscal, conforme demonstra Roque Carrazza:

De fato, quem cria tributos pode, por igual modo, aumentar a carga tributária (agravando a alíquota ou a base de cálculo da exação), diminuí-la (adotando o procedimento inverso) ou, até suprimi-la, por intermédio da não tributação pura e simples. Pode, ainda, isentar tributos. Tudo vai depender de uma decisão política, a ser tomada, de regra (há exceções), pela própria entidade tributante (CARRAZZA, 2015, p. 1031). 
Dentre as possíveis desonerações tributárias, o incentivo fiscal figura como gênero, abrangendo as isenções ou reduções da base de cálculo e alíquotas, os créditos presumidos e os descontos pela antecipação do recolhimento de tributos, em meio a outras manifestações do direito premial.

Por meio dos incentivos fiscais, certifica o Professor Carrazza que a pessoa política tributante estimula os contribuintes:

[...] a fazerem algo que a ordem jurídica considera conveniente, interessante ou oportuno (por exemplo, instalar indústrias em região carente do País). Este objetivo é alcançado por intermédio da diminuição ou, até, da supressão da carga tributária. Os incentivos fiscais manifestam-se sob a forma quer de imunidade (v.g. imunidade de ICMS ás exportações de produtos industrializados), quer de isenções tributárias (por exemplo, isenção de IPI sobre as vendas de óculos (CARRAZZA, 2015, p. 1035).

As imunidades consistem em vedações previstas no texto constitucional, impedindo a incidência de lei ordinária de tributação sobre determinado fato, ou em detrimento de determinada pessoa ou categoria de pessoas. As isenções tributárias, por sua vez, são consideradas dispensas legais de tributos devidos. Exclui o próprio fato gerador, ou seja, impede que o crédito se constitua (MACHADO, 2016, p. 231).

Os incentivos fiscais exigem uma contrapartida do contribuinte e, nessa medida, estimulam a realização de determinadas condutas, que vêm ao encontro dos interesses públicos. Ao contrário, os benefícios fiscais independem da contrapartida do contribuinte beneficiado. Destarte, 
por não passarem de favores fiscais, demandam, para serem validamente concedidos, sólido respaldo no princípio da igualdade e nos valores ínsitos a nosso sistema jurídico. (CARRAZZA, 2015, p. 1035).

Nessa linha, enquanto as "não sujeições tributárias", segundo o jurista português José Casalta Nabais:

[...] são medidas fiscais de natureza estrutural que estabelecem delimitações negativas expressas da incidência, inscrevendo-se portanto na política fiscal ou política de obtenção de receitas fiscais, os benefícios fiscais são medidas de carácter excepcional instituídas para tutela de interesses públicos extrafiscais relevantes que se revelem superiores aos da própria tributação que impedem, integrando-se assim na política extrafiscal ou política de prossecução de objectivos económicos e sociais por via fiscal. (NABAIS, [201?], p. 15).

$\mathrm{O}$ autor distingue ainda os "desagravamentos" fiscais dos benefícios fiscais quanto à respectiva durabilidade. Os primeiros constituem medidas dotadas de estabilidade, que são medidas por natureza duradouras, enquanto que os benefícios fiscais se apresentam como medidas conjunturais, como medidas temporárias. (NABAIS, [201?], p. 16).

No que se refere aos subsídios e as subvenções, por consistirem em ajudas ou auxílios pecuniários por parte do Estado, ou seja, dispêndio de dinheiro público dirigido ao âmbito privado, não há que se falar em benefícios ou incentivos fiscais.

Independentemente da espécie, sejam benefícios fiscais sejam 
incentivos fiscais ou até mesmo subsídios ou subvenções, uma vez atuando como instrumento de fomento ao desenvolvimento sustentável e a favor da proteção ambiental, deve sempre haver o respeito aos princípios constitucionais gerais e tributários, inclusive o princípio da capacidade contributiva. Caso contrário, referidos mecanismos tributários tomarão roupagem de meras vantagens ou privilégios pessoais, sem alcançar o real objetivo, qual seja, o interesse coletivo. Como pode ser observado nos dizeres de Nabais:

[...] Mas os limites à utilização dos benefícios fiscais, mesmo com objectivos de protecção do meio ambiente, arrancam do seu próprio conceito e da distinção que é usual fazer entre eles que, não raro, desencadeia regimes jurídicos diferenciados. Pois bem, quanto ao seu conceito, devemos referir que os benefícios fiscais se enquadram numa noção mais ampla - a noção de desagravamentos fiscais - que integra: de um lado, as não sujeições tributárias (ou desagravamentos fiscais stricto sensu), cuja modalidade mais significativa é constituída pelas chamadas exclusões tributárias (que estão para as não sujeições tributárias como as isenções estão para os benefícios fiscais); de outro, os benefícios fiscais. (NABAIS, [201?], p.14).

Assim, as desonerações consistem em espécies excepcionais do sistema tributário nacional, sendo, portanto, justificadas as suas utilizações apenas diante de interesses de maior envergadura, tal qual a proteção ambiental.

A título de ilustração, pode ser destacado o direcionamento do 
IPTU (imposto predial e territorial urbano), bem como do ICMS (imposto sobre circulação de mercadoria e serviços), identificados como IPTU verde e ICMS ecológico, respectivamente, ás finalidades ambientalmente protetivas. O Estado do Paraná foi o primeiro Estado da federação a adotar esta prática financeira de estímulo ao meio ambiente (Lei estadual $n^{\circ}$ 9.491/90 e Lei Complementar estadual no 59/91).

Com isso, pode ocorrer maior repasse da arrecadação do ICMS pelos Estados aos Municípios que atendam a determinados critérios ambientais, estabelecidos em leis estaduais, funcionando como instrumento de incentivo a criação e defesa de áreas ambientalmente protegidas.

Note-se que a política do ICMS Ecológico representa uma clara intervenção positiva do Estado, como fator de regulação não coercitiva, através da utilização de uma forma de subsídio. Tal incentivo representa um forte instrumento econômico extrafiscal com vista à consecução de uma finalidade constitucional de preservação. Promovendo, com isso, justiça fiscal e influenciando nas ações voluntárias dos municípios que buscam um aumento de receita e de uma melhor qualidade de vida para suas populações (SCAFF; TUPIASSU, 2005, p. 735).

No caso do "IPTU verde", a legislação pode prever descontos na alíquota para imóveis que possuam árvores na fachada, áreas permeáveis no terreno ou ainda que adotem medidas como captação de água da chuva e reciclagem de lixo. A progressividade do imposto pode ter caráter extrafiscal, desde que obedecido o disposto no parágrafo $1^{\circ}$ do artigo 156 e no artigo 182, ambos da Constituição Federal.

No julgamento da ADPF 101/DF, de maneira vinculante, validou a vedação regulamentar a importação de pneus usados, que afeta diretamente o desenvolvimento sustentável e a saúde, já que os resíduos 
sólidos produzem um grande passivo ambiental. Por óbvio, repercute na ordem econômica, todavia neste caso concreto, privilegiou-se a proteção ambiental (Rel. Ministra Carmen Lúcia, em 24.06.09).

Heleno Torres assevera que:

O incentivo fiscal ambiental não pode ser concebido como um "favor", mas uma "despesa pública" do Estado para que o particular possa substitui-lo com mais eficácia onde sua presença seja imprescindível. Assim, quando empregados adequadamente, os benefícios ambientais neutralizam as supostas perdas de arrecadação. Incentivos à inovação e ao desenvolvimento de tecnologias menos ofensivas ao meio ambiente são fundamentais para o desenvolvimento sustentável. Deveras, não se deve conferir benefícios fiscais para o que é dever dos particulares. (TORRES, 2012b, p. 2).

As taxas ambientais federais de diversas especificidades, demonstram o caráter da tributação ambiental por meio do poder de polícia, com o objetivo de limitar os direitos individuais em benefício do interesse público.

Merece destaque dentre as contribuições de intervenção no domínio econômico, a CIDE - combustíveis, que tem parte de sua destinação direcionada para projetos de preservação ambiental. Os recursos arrecadados são destinados ao subsídio de transporte de álcool combustível, gás e derivados do petróleo e financiamento de projetos ambientais específicos como a recuperação ambiental e o fomento à pesquisa conforme estabelece a Lei $n^{\circ} 10.636 / 2002$.

No que diz respeito ao Imposto Territorial Rural, é nítido o seu 
caráter extrafiscal. Instituído com vistas ao desestimulo de latifúndios improdutivos, também possui mecanismos de incentivo à preservação do meio ambiente. O artigo 104 da Lei $n^{0} 8.171 / 91$ prevê a isenção do ITR relativamente às áreas de preservação permanente, de reserva legal e de interesse ecológico para a proteção dos ecossistemas.

Os tributos de maneira geral, podem ser mais eficazes, como a desoneração de serviços focados em saneamento ambiental, redução de alíquotas do IPI e do ICMS, se na produção de bens e mercadorias forem empregadas tecnologias menos poluentes.

Os impostos de renda, de importação, de exportação, sobre produtos industrializados, sobre circulação de mercadorias e serviços, sobre a propriedade imóvel e de veículo automotor, podem contemporizar outras exações tendentes à proteção e à conservação ambiental.

Em alguns Estados, pode-se verificar algumas legislações referentes ao Imposto sobre a Propriedade de Veículos Automotores, que diferenciam as alíquotas considerando o combustível utilizado e seu grau de poluição. Os Estados também podem considerar o Imposto sobre Transmissão causa mortis e Doação de Quaisquer Bens ou Direitos com uma tributação diferenciada para aqueles imóveis tidos como produtivos ou de interesse ambiental entre outras situações similares.

As políticas públicas ambientais têm na maioria das vezes, objetivos de incentivar ou desestimular comportamentos. O imposto cumpre esta função de maneira mais acentuada como observa Fiorillo; Marques (2005, p. 58) que:

$\mathrm{Na}$ maioria dos casos apresentados no Texto Maior verificamos que a alternativa encontrada pelo legislador ordinário no sentido de adequar a chamada tributação ambiental na modalidade 
dos impostos segue no sentido da concessão de isenções, incentivos fiscais, benefícios e assim por diante.

Embora não sendo objeto de análise do presente artigo, é interessante ressaltar a Proposta de Emenda Constitucional no 92/2015, em tramitação no Senado Federal, com o direcionamento para incluir no texto constitucional, medidas tributárias ambientais para os tributos: ICMS, IPTU, IPVA e Contribuições dispostas no art. 149. Se tal proposta for aprovada, certamente o Brasil terá critérios estabelecidos como políticas públicas de estado, para efetivação das questões tributárias no âmbito do meio ambiente.

A intervenção do Estado sobre o domínio econômico ambiental busca corrigir as falhas trazidas pelas externalidades ecológicas, compatibilizando a sistemática financeira com a preservação ambiental, não obstante haver a disponibilidade de instrumentos legais. Para tanto, é substancial o aperfeiçoamento dessa sistemática de modo a garantir a segurança jurídica.

\section{CONCLUSÃO}

Fruto do desenvolvimento industrial e econômico desmedido, o dano ambiental tomou proporções alarmantes, restando a presente geração a árdua tarefa de reduzir ao máximo seus efeitos.

O movimento internacional estabeleceu diretrizes e deveres ás Nações para que, no âmbito interno, desenvolvessem planos de proteção ao meio ambiente e fomento ao desenvolvimento sustentável. O desafio é a conciliação entre o desenvolvimento econômico e os limites impostos 
pela proteção ambiental, frente ás ilimitadas necessidades humanas e os limitados recursos naturais.

No Brasil, a Constituição Federal de 1988 inaugurou a Ordem Constitucional Ambiental, privilegiando o desenvolvimento sustentável. E, através da interpretação aberta e sistemática do texto constitucional, é evidente o uso do direito tributário para a consecução das políticas públicas necessárias ao cumprimento do desenvolvimento nacional.

Portanto, o Estado intervém na ordem econômica visando garantir o desenvolvimento sustentável por intermédio da extrafiscalidade que, por sua vez, é capaz de incentivar ou restringir as ações ou omissões dos contribuintes.

A partir daí depreende-se, então, que a tributação pode e deve servir como instrumento de política pública ambiental. Contudo, não há que se falar na criação de espécies tributárias específicas, mas sim o direcionamento do atual sistema tributário do desenvolvimento sustentável. Deve ser salientado que não há necessidade de criar novos tributos, e sim, como distribuir os recursos arrecadados previstos no Sistema Tributário Nacional vigente, aplicados à implementação de políticas públicas em todos os níveis de governo, que devem oferecer condições para compatibilizar o direito ao desenvolvimento com a proteção do direito ambiental (meio ambiente), sendo ambos direitos garantidos constitucionalmente.

É preciso que o meio ambiente seja preservado, não através de uma tributação acentuada e sim com estímulos ou benefícios, entre eles destacando-se aqueles projetos que contemplam planejamentos ambientais que preservem e recuperem o meio ambiente degradado.

Somente serão constitucionais os incentivos fiscais que buscarem o equilíbrio do desenvolvimento sócio econômico entre as 
diferentes regiões do país.

As políticas públicas são bem-vindas, mas toda a sociedade é também responsável pelo desenvolvimento e pelas próprias políticas. Se estas não estiverem aliadas a outros movimentos ou comportamentos da própria comunidade, não haverá a efetivação das políticas estabelecidas. Para a qualidade de vida e o desenvolvimento sustentável, é necessário que um conjunto de informações seja efetivamente tratado.

$\mathrm{O}$ artigo 151 da Constituição Federal veda a instituição de tributo que não seja uniforme em todo território nacional, admitindo a concessão de incentivos fiscais destinados a promover o equilíbrio do desenvolvimento sócio-econômico entre as diferentes regiões do país. De igual porte, tem-se que qualquer subsídio ou isenção, redução de base de cálculo, concessão de crédito presumido, anistia ou remissão relativos aos tributos somente poderá ser concedido por lei específica (art. 150 - $\S$ $6^{\mathrm{o}}$ da CF). Com estes institutos que integram a extrafiscalidade, os entes tributantes poderão estimular os contribuintes a fazer algo que a ordem pública considera conveniente ou oportuno de interesse ambiental para a coletividade.

A extrafiscalidade também se manifesta pelos desestímulos fiscais que estimulam contribuintes a não assumirem determinadas condutas, que embora sendo lícitas, são havidas por impróprias sob o aspecto político, econômico e social.

\section{REFERÊNCIAS}

AMADO, Frederico. Direito ambiental. 5. ed. São Paulo: Método, 2014. 
BERNARDI, Renato. Tributação ecológica: o uso ambiental da extrafiscalidade e da seletividade tributárias. Rio de Janeiro; Forense, 2008.

BONFIM, Diego. Extrafiscalidade. identificação, fundamentação, limitação e controle. São Paulo: Noeses, 2015.

BRASIL. Constituição (1988). Constituição da República Federativa do Brasil. Organização de Alexandre de Moraes. São Paulo: Atlas, 2012.

CARRAZZA, Roque Antônio. Curso de direito constitucional tributário. São Paulo: Malheiros, 2008.

CARRAZZA. Roque Antônio. Curso de direito constitucional tributário. 30. ed. São Paulo: Malheiros. 2015.

CAVALCANTE, Denise Lucena. Sustentabilidade financeira em prol da Sustentabilidade ambiental. In: GRUPENMACHER, Betina Trieger et al. Novos horizontes da tributação: um diálogo luso-brasileiro. Coimbra: Almedina.2012.

COSTA, Regina Helena. Apontamentos sobre a Tributação Ambiental no Brasil. In: TORRES, Heleno Taveira (Org). Direito tributário ambiental. São Paulo: Malheiros, 2005.

DECLARAÇÃO DO RIO. DECLARAÇÃO DO RIO SOBRE MEIO AMBIENTE E DESENVOLVIMENTO. Rio de Janeiro, 1992. Disponível em: http://www.onu.org.br/rio20/img/2012/01/rio92. pdf. Acesso em: 27 out. 2016.

DERANI, Cristiane. Aplicação dos princípios do direito ambiental para o desenvolvimento sustentável. In: TORRES, Heleno Taveira (Org). Direito tributário ambiental. São Paulo: Malheiros, 2005. p. 641-652. 
DEZEN JUNIOR, Gabriel. Curso completo de direito constitucional. Brasília: Vestcon. 2003.

FERREIRA, Eduardo Paz. Valores e interesses: desenvolvimento econômico e política comunitária de cooperação. Coimbra: Almedina, 2004.

FIORILLO, Celso Antônio Pacheco; FERREIRA, Renata Marques. Direito ambiental tributário. São Paulo: Saraiva. 2005.

GRAU, Eros Roberto. A ordem econômica na constituição de 1988. São Paulo: Malheiros. 2005.

GREY, Natália de Campos. Tributação do meio ambiente. Revista Jurídica Tributária, Porto Alegre, v. 2, n. 5, p. 89-111, abr./jun. 2009.

MACHADO, Hugo de Brito. Curso de direito tributário. 37. ed. Malheiros: São Paulo. 2016.

MEDEIROS, Neuci Pimenta de. Parâmetros constitucionais para política tributária extrafiscal voltada à proteção do meio ambiente. Revista Argumentum, Marília, v. 11, n. 12, p. 117-136, 2011.

MILARÉ, Édis. Direito do ambiente: doutrina, jurisprudência, Glossário. 5. ed. Revista dos Tribunais, 2007.

NABAIS, José Casalta. Tributos com fins ambientais. Lisboa: ICJP, [201?]. Disponível em: <http://www.icjp.pt/sites/default/files/ media/722-1115.pdf>. Acesso em: 27 out. 2016.

RIBEIRO, Maria de Fátima; FERREIRA, Jussara Suzi Assis B. O papel do estado no desenvolvimento econômico sustentável: reflexões sobre a tributação ambiental como instrumento de políticas públicas. In: TORRES, Heleno Taveira (Org). Direito tributário ambiental. São Paulo: Malheiros, 2005. p. 653-673. 
ROTHMANN, Gerd Willi. Tributação, sonegação e livre concorrência. In: Roberto Ferraz (Coord.). Princípios e limites da tributação. 2. ed. São Paulo: Quartier Latin, 2009. p. 337-364.

SABBAG, Eduardo. Manual de direito tributário. 5. ed. São Paulo: Saraiva, 2013.

SCAFF, Fernando Facury; TUPIASSU, Lise Vieira da Costa. Tributação e políticas públicas: o ICMS ecológico. In: TORRES, Heleno Taveira (Org). Direito tributário ambiental. São Paulo: Malheiros, 2005.

TORRES, Heleno Taveira. Descompasso entre as políticas ambiental e tributária. São Paulo: Consultor Tributário, 2012a. Disponível em:< http://www.conjur.com.br/2012-jun-20/consultortributario-descompasso-entre-politicas-ambiental-tributaria $>$. Acesso em: 15 jul. 2016.

\section{TORRES, Heleno Taveira. A tributação orientada à} sustentabilidade ambiental. São Paulo: Consultor Tributário, 2012 b. Disponível em: < http://www.idtl.com.br/artigos/397.pdf>. Acesso em: 15 jul. 2016.

TORRES, Heleno Taveira (Org). Direito tributário ambiental. São Paulo: Malheiros, 2005.

Como citar: PAYÂO, Jordana Viana. RIBEIRO, Maria de Fátima. A extrafiscalidade tributária como instrumento de proteção ambiental. Revista do Direito Público, Londrina, v. 11, n. 3, p.276-310, dez. 2016. DOI: 10.5433/1980-511X.2016v11n3p276. ISSN: 1980-511X.

Submetido em 25/11//2016

Aprovado em 05/12/2016 